\title{
Hyperspectral Radiometry on Biogeochemical-Argo Floats: A Bright Perspective for Phytoplankton Diversity
}

By Emanuele Organelli, Edouard Leymarie, Oliver Zielinski, Julia Uitz, Fabrizio D’Ortenzio, and Hervé Claustre

By installing biogeochemical sensors on 1,000 autonomous Argo profiling floats across the globe, the Biogeochemical (BGC)-Argo program is the only network capable of providing detailed observations of the physics, chemistry, and biology of the top 2,000 m of our ocean up to every 10 days, even in remote regions and during unfavorable conditions for manual sampling. This rapidly expanding network will yield large amounts of data that will help us understand marine ecosystems and biogeochemistry, evaluate the impact of increasing human-derived pressures on Earth's climate, and develop science-based solutions for sustainable ocean and climate management.

Officially established in 2016, the International BGC-Argo program has built its mission on five science pillars and two management needs. One of the grand science challenges, and also a primary element for improving management of all living marine resources, is observing the composition of phytoplankton communities (BGC-Argo Planning Group, 2016). These microscopic, drifting, unicellular algae use sunlight and seawater to transform the carbon dioxide exchanged between the atmosphere and the ocean into oxygen and complex organic compounds. Phytoplankton create enough energy to benefit the entire food chain, from zooplankton to top predators.

Phytoplankton are so diverse that collectively they maintain a variety of biogeochemical and ecosystem functions, including carbon cycling and storage. These organisms display a wide variety of types, sizes, shapes, photosynthetic efficiencies, pigmentations, and light absorption properties. While various methods can be used to identify phytoplankton, the traditional method requires water samples taken at sea and experts using microscopes to identify species, distinguishing features such as size and shape. A newer, more high-tech method employs satellite observations of ocean color to provide information on cellular

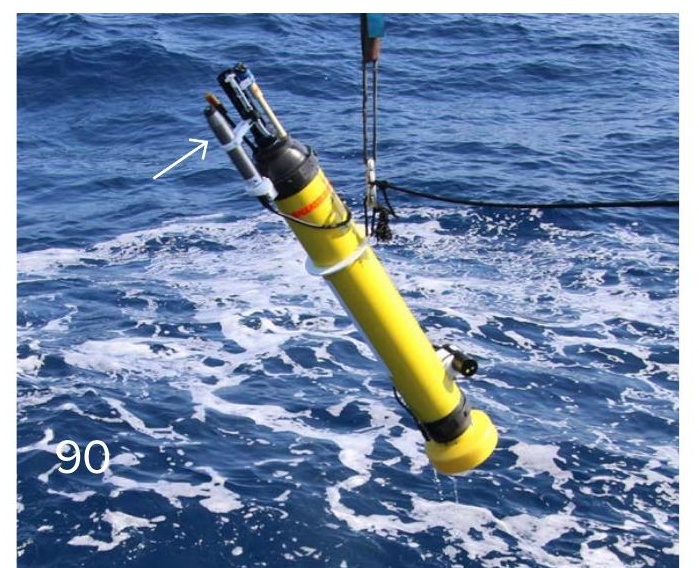

traits, which can in turn be used to identify phytoplankton types. Although they offer the highest spatial coverage of any autonomous systems, satellite observations are limited to providing information only for surface ocean waters.

In water, cellular traits are determined by measuring the amount of ultraviolet (UV) and visible (VIS) light coming from the sun. Water absorbs red light near the surface, while detrital particles and dissolved organic matter reduce the availability of light in the UV and blue spectral bands. Phytoplankton pigments absorb UV and VIS light at different wavelengths, and pigmentation is different across the various groups. Thus, changes in the colors of the light fields detected in seawater reflect various types of phytoplankton. Currently, the four color bands available on the radiometric sensors implemented on the global BGC-Argo array are not sufficient to characterize the spectral variability of the underwater light field, so the diversity of phytoplankton communities cannot be resolved by currently available sensors on the floats. Hyperspectral radiometry-capturing light over many wavelengths, enabling tens or hundreds of colors to be recognizedpoints the way forward (Jemai et al., 2021).

European scientists have cooperated to upgrade the BGC-Argo sensor package with a hyperspectral radiometer, which is mounted at the top of the float to avoid platform self-shading (Figure 1). This hyperspectral instrument senses the sun's radiant energy in the water at 140 color bands, from $320 \mathrm{~nm}$ to $780 \mathrm{~nm}$, every $3.3 \mathrm{~nm}$. In 2021, the first at-sea tests of this technology involved deploying five newly configured BGC-Argo floats in two different environments: the Baltic Sea and the Mediterranean Sea. During their voyages, the new floats collected data for characterizing the dynamics of the submarine light field down to $300 \mathrm{~m}$ depth, from phytoplankton bloom to post-bloom conditions and during deep chlorophyll maxima (DCM) formation. The spectral signatures captured during two high-chlorophyll DCM events show that the descending light was absorbed differently at the two sites (Figure 2). In the Baltic Sea, the most absorbed colors are blue and

FIGURE 1. Deployment of a Biogeochemical-Argo float (APEX, Teledyne Webb Research) equipped with a hyperspectral radiometer (RAMSES, TriOS $\mathrm{GmbH}$ ). The white arrow points to the RAMSES radiometer (shiny gray instrument). Hyperspectral radiometers on APEX and PROVOR (NKE Marine Electronics) BGC-Argo floats have been implemented within the European Union's HORIZON 2020 research and innovation program through the EA-RISE project (grant number 824131) and the SpectralArgo-N project funded by the German Ministry of Research (grant number 03F0825A). Image credit: Emilie Diamond Riquier, IMEV - Institut de la Mer de Villefranche (France) 
FIGURE 2. BGC-Argo floats equipped with hyperspectral radiometers capture the optical signatures of phytoplankton communities and their compositions. The spectral bands at which light disappears provide information on pigments and thus on phytoplankton types present. Vertical profiles of hyperspectrally resolved downwelling irradiance (radiant energy from the sun) show, at the level of the deep chlorophyll maxima (DCM; thick blue line), a maximum of the remnant light around $560 \mathrm{~nm}$ for the brownish waters of the Baltic Sea (a), and around $480 \mathrm{~nm}$ for the blue Mediterranean (b).

green. While blue is mainly absorbed by substances other than phytoplankton, green is mostly absorbed by diatoms and dinoflagellates. Indeed, diatoms and dinoflagellates contain the highest per cell concentrations of green-light-absorbing pigments (Organelli et al., 2017). In the Mediterranean Sea, the prevailing remnant light at the DCM and below is blue-green. This color is consistent with low pigment content, and thus communities composed of cyanobacteria and other small phytoplankton.

The combination of hyperspectral radiometry and Argo technology is especially promising for monitoring ecosystem changes and for building long-term records on phytoplankton diversity through the water column. By using light bands that are specifically targeted to discriminate among different phytoplankton types, we can greatly improve our knowledge of oceanic carbon stocks, pathways, and fluxes. Primary production is better constrained when BGC-Argo radiometric data are integrated into marine biogeochemical models.

The upgraded hyperspectral capability of BGC-Argo will also be beneficial for the management of living resources and ecosystem services (e.g., habitat suitability, fish stocks, and recruitment) and for biohazard surveillance (i.e., harmful algal blooms). Some species of phytoplankton are harmful due to their ability to massively proliferate or produce toxins. These toxins can affect a wide range of organisms, including fishes, seabirds, mammals, and humans. Because of specific pigments and high abundances, these harmful species modify the light in an easily recognizable manner. With hyperspectral radiometers, the BGC-Argo network may become a pillar for monitoring biohazards and the establishment of an early warning system for harmful phytoplankton (Figure 3) in the global ocean as well as in regional seas. This capability could be expanded to monitor toxic species by developing synergies with other optical observations from BGC-Argo or remote-sensing technologies (e.g., lidar).

BGC-Argo radiometry extends spacebased observations of ocean color into the water column, and synergies have already been developed for validating satellite products. A novel synergy with
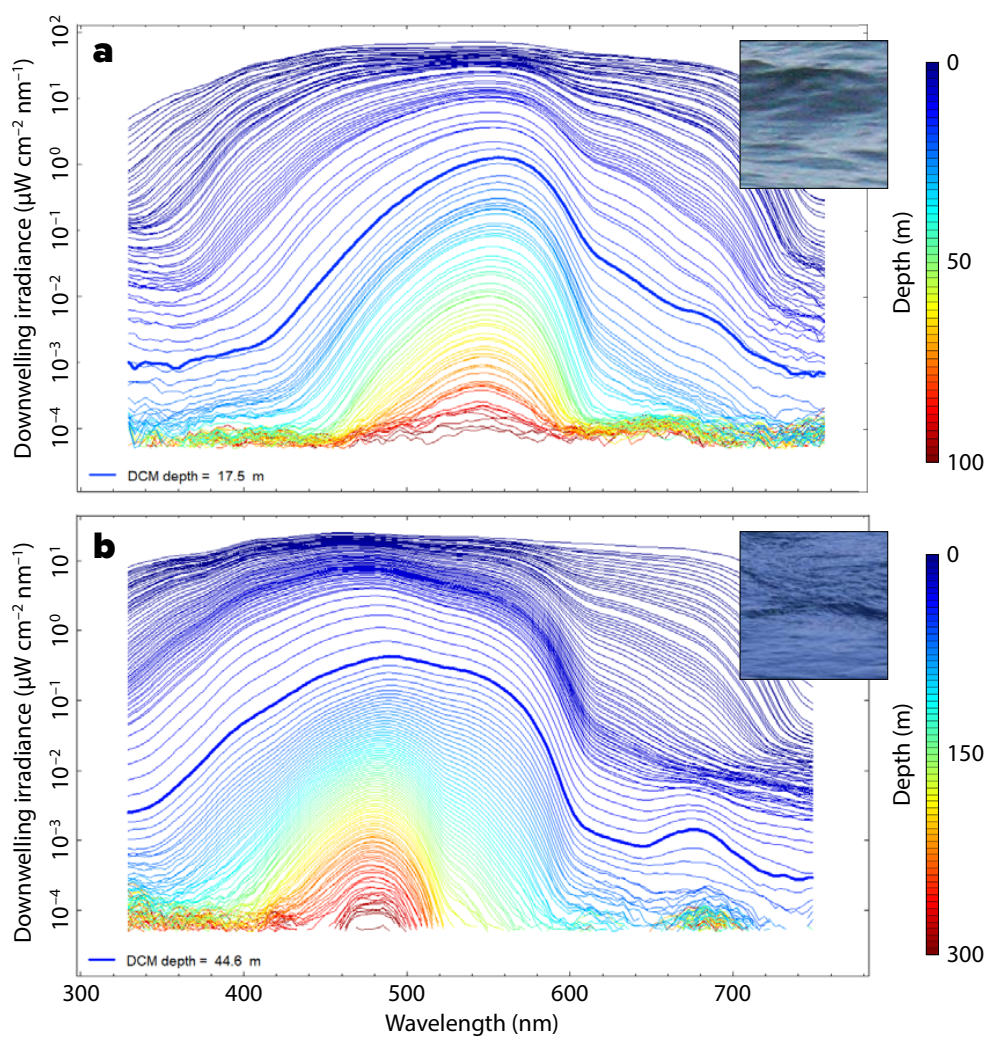

hyperspectral floats will help to build a three-dimensional view of phytoplankton diversity and a "digital twin of the ocean" to allow monitoring of ocean health and carbon and energy flows throughout the food web, and to support management actions toward maintaining ecosystem resilience.

\section{REFERENCES}

BGC-Argo Planning Group. 2016. The Scientific Rationale, Design and Implementation Plan for a Biogeochemical-Argo Float Array. K. Johnson and H. Claustre, eds, Ifremer, 65 pp., https://doi.org/10.13155/46601. Jemai, A., J. Wollschläger, D. Voß, and O. Zielinski. 2021. Radiometry on Argo floats: From the multispectral state-of-the-art on the step to hyperspectral technology. Frontiers in Marine Science 8:676537, https://doi.org/10.3389/fmars.2021.676537.

Organelli, E., C. Nuccio, L. Lazzara, J. Uitz, A. Bricaud, and L. Massi. 2017. On the discrimination of multiple phytoplankton groups from light absorption spectra of assemblages with mixed taxonomic composition and variable light conditions. Applied Optics 56(14):3,952-3,968, https://doi.org/10.1364/A0.56.003952.

ARTICLE DOI: https://doi.org/10.5670/oceanog.2021.supplement.02-33

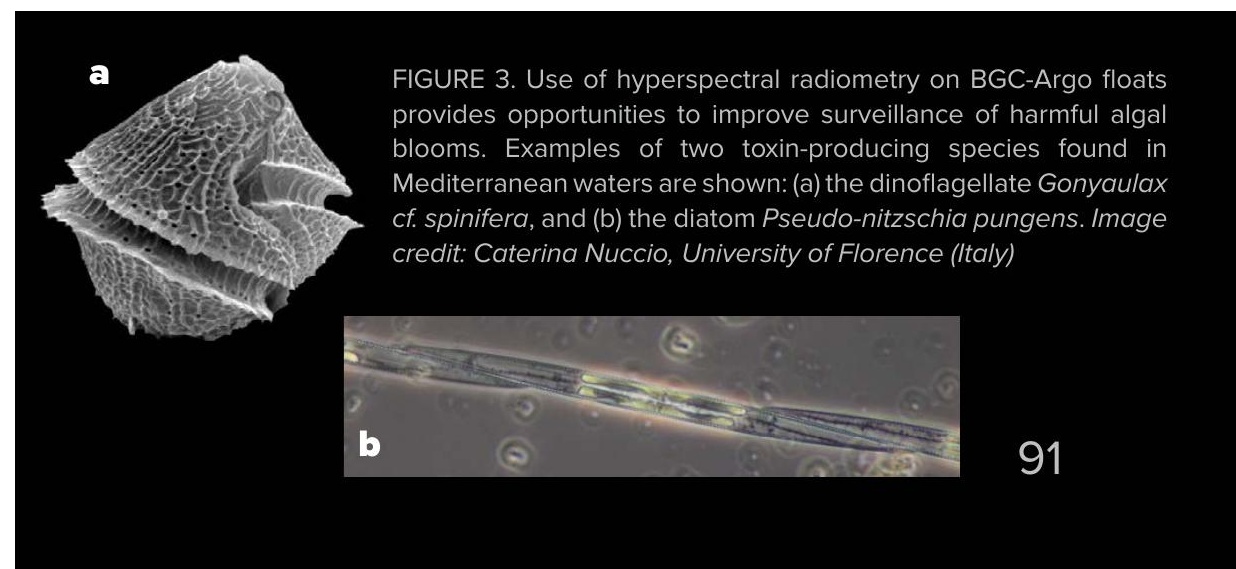




\section{AUTHORS}

Emanuele Organelli (emanuele.organelli@cnr.it), National Research Council (CNR), Institute of Marine Sciences (ISMAR), Italy. Edouard Leymarie, CNRS Sorbonne Université, Laboratoire d'Océanographie de Villefranche, Villefranche sur mer, France. Oliver Zielinski, Center for Marine Sensors (ZfMarS), Institute for Chemistry and Biology of the Marine Environment (ICBM), Carl von Ossietzky Universität Oldenburg, Germany, and German Research Center for Artificial Intelligence (DFKI), Marine Perception Research Department, Germany. Julia Uitz, Fabrizio D'Ortenzio, and Hervé Claustre, CNRS - Sorbonne Université, Laboratoire d'Océanographie de Villefranche, Villefranche sur mer, France.

\section{ARTICLE CITATION}

Organelli, E., E. Leymarie, O. Zielinski, J. Uitz, F. D'Ortenzio, and H. Claustre. 2021. Hyperspectral radiometry on Biogeochemical-Argo floats: A bright perspective for phytoplankton diversity. Pp. 90-91 in Frontiers in Ocean Observing: Documenting Ecosystems, Understanding Environmental Changes, Forecasting Hazards. E.S. Kappel, S.K. Juniper, S. Seeyave, E. Smith, and M. Visbeck, eds, A Supplement to Oceanography 34(4), https://doi.org/10.5670/oceanog.2021.supplement.02-33.

\section{COPYRIGHT \& USAGE}

This is an open access article made available under the terms of the Creative Commons Attribution 4.0 International License (https://creativecommons.org/ licenses/by/4.0/), which permits use, sharing, adaptation, distribution, and reproduction in any medium or format as long as users cite the materials appropriately, provide a link to the Creative Commons license, and indicate the changes that were made to the original content. 